\title{
United We Stand
}

\author{
Myrella Roy
}

$\mathrm{T}$ The Arab Spring undoubtedly epitomized unity during the year 2011. Whether driven by economic hardship or democratic yearning, citizens around the world have joined forces to courageously claim their rights, demand change, and take charge of their destiny. As history keeps reminding us, such rallying by no means guarantees victory, but it most certainly lends weight to a common cause and improves the chances of success. Although the Canadian Society of Hospital Pharmacists (CSHP) cannot lay claim to such valorous deeds, many of its accomplishments in 2011 occurred under the banner of unity.

CSHP Council took charge of the Society's destiny by adopting a new 3-year strategic plan (www.cshp.ca/aboutUs/ strategicPlan_e.asp). According to its Vision 2014, CSHP will strive to be the leading influence on the advancement of hospital pharmacy practice in Canada, by equipping pharmacists to practise to their full scope, advocating for the profession, collaborating with critical stakeholders, and fostering engagement and networking among its members. Similarly, the Board of Trustees of the CSHP Foundation hired consultants to conduct a situational analysis and provide strategic fund-raising counsel. The consultants' observations and recommendations informed discussions during the Foundation Board's own strategic planning session in August 2011.

Thanks to the new online portal MY.CSHP.ca, launched in April 2011, CSHP members can more readily connect with colleagues from the hospital community by searching the membership directory. This association management system also allows members to manage their personal and address information, pay their annual membership fees, register for CSHP conferences, and donate to the CSHP Foundation. Furthermore, members can now apply for malpractice insurance and renew their policy coverage online through the portal of Trisura, CSHP's new insurance carrier.

CSHP joined forces with BIOTECanada, the Canadian Association for Pharmacy Distribution Management, the Canadian Association of Chain Drug Stores, the Canadian Generic Pharmaceutical Association (CGPA), the Canadian Medical Association (CMA), the Canadian Pharmacists Association (CPhA), and Canada's Research-Based Pharmaceutical Companies ( $\mathrm{Rx} \& \mathrm{D})$ to tackle the escalating problem of drug shortages. The formation of this working group was prompted by a letter from the federal minister of health to the 3 major associations of pharmaceutical manufacturers, asking that they voluntarily disclose information about drug supply. In early June 2011, CSHP collaborated with CMA and CPhA to conduct a survey gauging the needs of our respective members as regards a national online system for monitoring drug shortages. Approximately 1300

pharmacists and physicians responded to the survey, expressing overwhelming support for such a system. Respondents also provided feedback on which information elements would be of most value in the proposed system. As a result of our collective efforts, CGPA and Rx\&D have agreed to collect information from their members about actual and impending drug shortages, and Saskatchewan Drug Information Services (www.druginfo.usask.ca/healthcare_professional/canadian_ drug_shortages.php) and, on behalf of SigmaSanté (the health care group purchasing organization for the Montréal and Laval regions in Quebec), the Pharmacy Practice Research Unit at the Centre hospitalier universitaire Sainte-Justine (www.fridaypm.ca) have consented to post the details on their public drug shortage websites. Given their limitations, these arrangements are intended as a short-term solution until a single, more robust national drug shortage monitoring system, with a greater scope of features and services, is launched, which we hope will happen in 2012. Throughout the past year, the media have continued to draw attention to the problem of drug shortages and have sought the views of CSHP as the influential voice of hospital pharmacy. Further information about CSHP's activities in this matter can be found at www.cshp.ca/advocacy/CSHP speaks/drugShortages_e.asp.

In the spirit of unity, CSHP's latest advocacy campaign, "Promoting and Supporting Interprofessional Practice Models" 
(see www.cshp.ca/advocacy/campaigns/index_e.asp), urged federal and provincial ministers and deputy ministers of health, chief executive officers and select vice presidents of hospitals and health care organizations, national and provincial pharmacy associations, and other national and provincial associations of health care professionals to optimize the integration of pharmacists within interprofessional care teams. The claim that adding a pharmacist to interprofessional care teams represents an asset to health care was substantiated with evidence of better health outcomes, improved patient safety, and reduced health care costs.

By means of a formal statement and information paper, CSHP also called for collaboration among pharmacist practitioners, educational institutions, accreditors of educational programs, and regulatory authorities in the development, delivery, and evaluation of pharmacy educational curricula designed to prepare pharmacy practitioners to meet the medication-related needs of society. Other Official Publications (www.cshp.ca/productsServices/officialPublications/type_e.asp) that were either added or revised during the past year are Outsourcing: Guidelines for Pharmacy Practice, Research: Statement on Supporting and Conducting Research, and Research: Guidelines on Conducting Research in Pharmacy.

CSHP continued to weigh in on issues raised by its stakeholders, namely, the Canadian Council for Accreditation of Pharmacy Programs (for the Accreditation Standards for Pharmacy Technician Education and the Accreditation Standards and Guidelines for the First Professional Degree in Pharmacy Programs), Health Canada (for the use of pseudo-Drug Identification Numbers for drug kits and the proposed Phase II of the Summary Basis of Decision Project), and the National Association of Pharmacy Regulatory Authorities (for the draft Model Standards of Practice for Canadian Pharmacy Technicians). CSHP further demonstrated intraprofessional and interprofessional collegiality by presenting at the first scientific days of the Moroccan Society of Clinical and Hospital Pharmacy in Rabat, Morocco, in April 2011 and at the First Hospital Pharmacy Congress of the Mexican Association of Hospital Pharmacists in Mexico City in July 2011; by hosting the annual trilateral joint officer meeting with the American Society of Health-System Pharmacists and the Mexican Association of Hospital Pharmacists in Ottawa in October 2011; and by appointing representatives to the Project Steering Committee for the Educational Program for Optimizing the
Use of Pharmacy Information and Information Technology of the Association of Faculties of Pharmacy of Canada, to the Antimicrobial Stewardship and Resistance Committee of the Association of Medical Microbiology and Infectious Disease Canada, to the Pharmacist Reference Group of Canada Health Infoway, and to the Subcommittee on Third Party Exposure to Methotrexate at Doses Used in Rheumatology of the Therapeutics Committee of the Canadian Rheumatology Association.

Of many more collective achievements, here are just a few highlights. A pay-per-view system was implemented for CSHP nonmembers who wish to purchase articles from the Canadian Journal of Hospital Pharmacy (CJHP) during the 6-month embargo period that follows publication. An outbound linking feature of the electronic version of CJHP (at www.cjhponline.ca) now links citations in CJHP articles to references in journals participating in CrossRef, PubMed, and/or PubMed Central. Finally, CSHP ended the 2010/2011 fiscal year well under budget, despite the sluggish Canadian economy.

In 2011, the CSHP staff continued to rally, supporting volunteer members, delivering core programs and services, and achieving strategic objectives. Although we wished Janet Lett a happy retirement from her position as Executive Assistant, we are fortunate to be able to avail ourselves of her corporate knowledge and skills for some time longer as Administrator of the CSHP Foundation. We have appointed Rosemary Pantalone to the permanent position of Executive Assistant and have made the following administrative reassignments: Pharmacy Specialty Networks (PSNs) to Desarae Davidson, Advocacy Agenda to Gloria Day, CSHP 2015 Project to Susan Korporal, and Awards Program to Robyn Rockwell. Shortly before the year's end, we congratulated Robyn Rockwell on the birth of her first-born, and Amanda Cuirrier accepted the interim position of Membership and Awards Administrator during Robyn Rockwell's maternity leave. Last but not least, we celebrated the 10th anniversary of CSHP employment of Desarae Davidson (Conference and PSN Administrator), Anna Dudek (Finance Administrator), and Laurie Frid (Operations Manager).

Coming together is a beginning, staying together is progress, and working together is success. -Henry Ford

Myrella Roy, BScPhm, PharmD, FCCP, is Executive Director of the CSHP. 